\title{
The development and validation of computer self-efficacy and outcome expectancy scales in a nonvolitional context
}

\author{
JOHN W. HENRY \\ Georgia Southern University, Statesboro, Georgia \\ and \\ ROBERT W. STONE \\ University of the Pacific, Stockton, California
}

\begin{abstract}
Computer self-efficacy and outcome expectancy scales were developed using 306 responses to a questionnaire distributed by a national mail survey to end users of computer systems in a variety of functional business areas. Confirmatory factor analysis using a structural equations approach was used to develop three scales. The scales were found to demonstrate satisfactory psychometric properties. The reliability coefficients for these scales were as follows: .85 for computer self-efficacy; .88 for work-related outcome expectancy; and .89 for personal outcome expectancy. The scales provide a strong foundation from which to refine the measurement of computer self-efficacy and outcome expectancy. From these refinements, empirical models that include self-efficacy and outcome expectancy as determinants of information technology acceptance at the individual level of analysis can be improved.
\end{abstract}

The introduction of computers into the workplace has elicited a large number of studies in the past 20 years. The information technology (IT) literature is replete with reports of computer attitude studies and how these attitudes affect computer use. In addition, anxiety (Igbaria \& Chakrabarti, 1990; Igbaria \& Parasuraman, 1989; Jacobson, Holder, \& Dearner, 1989) and vague concepts such as "computerphobia" and "technophobia" have been related to resistance to IT (Jay, 1981). Specifically, IT refers to any product whose underlying technological base is composed of computer or communications hardware and software (Cooper \& Zmud, 1990).

Attitudes have received the most attention in IT research (LaLomia \& Sidowski, 1991). The notion that attitudes affect behavior has been proposed for years (Oskamp, 1977). For example, the work of Fishbein and Ajzen (1975) identified specific conditions under which attitudes should predict behavior. Fishbein and Ajzen developed the theory of reasoned action (TRA), which proved successful in predicting behavior across numerous contexts. The TRA model posits that actual behavior (e.g., computer system use) is influenced by behavioral inten-

The authors' names are listed randomly. J.W.H. is in the Department of Management, College of Business Administration, Georgia Southern University. R.W.S. is in the Department of Management and Information Systems, Eberhardt School of Business, University of the Pacific. The authors gratefully acknowledge financial support from the Faculty Research Committee at Georgia Southern University. Correspondence should be addressed to J. W. Henry, Department of Management, College of Business Administration, Georgia Southern University, Statesboro, GA 30460-8152 (e-mail: jhenry@gsaix2.cc.gason.edu). tions regarding the behavior, while behavioral intentions are affected by attitudes toward the behavior, subjective norms, beliefs and evaluations, and normative beliefs and motivation to comply (Davis, Bagozzi, \& Warshaw, 1989). This work was later adapted to IT research in the form of the technology acceptance model (TAM). The TAM theoretically links external variables, perceived usefulness, and ease of use of a computer system to actual computer system use through attitudes and behavioral intentions toward using the computer system (Davis, 1986; Davis et al., 1989). The TAM was relatively successful in predicting computer usage in a number of studies in which IT use was voluntary (Davis et al., 1989). However, over time, inconsistencies in studies using attitude scales were noticed. Gutek, Winter, and Chudoba (1992) have posited that these inconsistencies may be due to the increase in nonvolitional IT use. Doll and Torkzadeh (1996) also stated that "where use is mandatory, measures of system-use may indicate only compliance, not effectiveness" (pp. 1-2).

In addition, LaLomia and Sidowski (1991) criticized attitude measures on three specific grounds. First, attitude measures rarely make any distinctions among mainframe, minicomputer, or personal computer experiences. Second, there is a lack of research relating attitudes to systems design and training. Finally, there is a lack of a theoretical foundation for most attitude scales. In their 1991 review, LaLomia and Sidowski found only three scales that encompassed cognitive, behavioral, and affective elements that would be theoretically consistent with any existing attitude scales. Moreover, LaLomia and Sidowski stated that attitude research has not been successful in addressing how attitudes are formed or changed. These problems are 
likely to escalate as IT use becomes increasingly nonvolitional. This may be especially true where IT focuses on semistructured and nonstructured problems, such as those amenable to decision support systems or expert systems, and not "simple-to-learn" systems such as word processors.

As mentioned previously, IT use has become more nonvolitional, inconsistency problems with attitude scales, which are a key component of models such as the TAM, have become a problem (Gattiker \& Hlavka, 1992; Gutek et al., 1992; LaLomia \& Sidowski, 1991; Pope-Davis \& Twing, 1991). Even with the wealth of available computer attitude studies, these attitude scales may not always be appropriate for measuring and predicting performance and intentions when computer usage is nonvolitional. In such a setting, attitude measures may be inconsistent predictors since attitudes appear as consistent predictors only in volitional settings (Gutek et al., 1992). In other words, measuring the success of IT with attitude scales may become troublesome and produce inconsistent results for the purpose of evaluating the success of a system as more and more systems become nonvolitional. Thus, there is a vital need for more encompassing constructs grounded in accepted theoretical paradigms in these settings, especially as IT becomes more oriented to end users (e.g., Visual Basic, Windows).

As noted, Gutek et al. (1992) suggested that attitudes associated with voluntary computer use may no longer be valid, reliable predictors of criterion variables such as job performance, IT satisfaction, and IT usage. We propose in this paper that the end users' beliefs in their own competency to make full use of IT and how its use affects desired personal and work outcomes drastically affects their perceptions of IT usefulness and subsequent IT satisfaction, job satisfaction, job performance, job commitment, and organizational commitment. Thus, the identification and isolation of constructs measuring the end users' beliefs in their competency to use IT and what successfully using IT accomplishes in terms of personal and work-related outcomes will become increasingly important.

As suggested by several researchers, it is important to focus on individual differences in cognition, affect, and behavior that individuals exhibit when nonvolitional IT is introduced into the workplace (Baronas \& Louis, 1988; Gutek et al., 1992; Nelson, 1990; Nelson \& White, 1990; Rafaeli \& Sutton, 1986; Zmud, 1979). The research described below is grounded in self-efficacy theory. It is proposed that expectations, as defined by Bandura (1986), are extremely important to the acceptance and successful use of IT in a nonvolitional context. In the past, many theories have been adapted from the behavioral sciences to explain the determinants of successful information systems. As noted, most of these studies have examined computer attitudes and anxiety as antecedents of IT use and satisfaction, probably the most frequently used variables to measure IT success (Igbaria \& Chakrabarti, 1990; Igbaria \& Parasuraman, 1989; Kwon \& Zmud, 1987; Pancer, George, \& Gebotys, 1992).

Some research has been conducted using self-efficacy scales and constructs similar to outcome expectancy to ex- plain IT success. However, these studies have been done primarily in volitional settings either with students or a single organization, which limits their generalizability (e.g., Davis et al., 1989; Gist, Schwoerer, \& Rosen, 1989; Hill, Smith, \& Mann, 1987). We have used variations of the scales described in past research (e.g., Gist et al., 1989; Hackett \& Betz, 1989; Meier, 1985, 1988). However, the results were inconsistent and did not strongly predict relevant outcome variables (e.g., satisfaction, performance) in organizational and classroom settings (Henry, 1989; Henry \& Martinko, 1997; Henry \& Stone, 1993; Henry, Stone, \& Pierce, 1995). Thus, we began a series of research studies based on our past findings, taking the best of each previous study to develop and refine an instrument that is theoretically and psychometrically sound and predicts relevant outcome variables in IT research - for example, performance, impact of IT, and job satisfaction (Henry \& Stone, 1994, 1995a, 1995b, 1995c).

\section{Theoretical Framework}

Self-efficacy theory (Bandura, 1982, 1986) emphasizes the impact of the individual's cognitive state on outcomes such as loss of control, low self-confidence, lowered achievement motivation, and perceptions of future outcomes. It provides a basis for describing behavioral and affective reactions to IT (Bandura, 1986; Baronas \& Louis, 1988; Martinko, Henry, \& Zmud, 1996; Meier, 1985; Seligman, 1990). Self-efficacy theory can be viewed as part of a larger group of psychological theories described as expectancy-value theories (Maddux, Norton, \& Stoltenberg, 1986). These theories propose that expectations are the primary determinants of behavioral and affective outcomes. Thus, self-efficacy theory proposes that an individual's expectations are the primary determinants of affective and behavioral reactions in numerous scenarios, involving motivation, performance, and feelings of frustration associated with repeated failure.

Bandura $(1977,1986)$ separated expectations into two distinct types affecting individual behavioral and affective outcomes: self-efficacy and outcome expectancy. Selfefficacy refers to an individual's belief that he/she possesses the requisite skills and abilities to accomplish an identifiable task. Self-efficacy determines the individual's level of persistence to learn a task and influences perceptions of future outcomes. Outcome expectancy refers to an individual's belief that task accomplishment leads to a desired outcome. It is defined as the consequence of an act and not the act itself. Both have separate and distinct impacts on individual behavior and affect, although Bandura (1986) stated that self-efficacy typically has a larger effect. Additionally, self-efficacy has a direct impact on outcome expectancy.

The four primary sources of self-efficacy, in order of importance, are task performance, vicarious experience, verbal persuasion, and physiological arousal (Bandura, $1977,1986)$. In the work context, these translate into actual experience, the influence of others in the immediate work environment, and the difficulty of the task (Gist \& 
Mitchell, 1992). The value of self-efficacy theory lies in the notion that not only is there a direct relationship between expectancies and behavioral and affective outcomes, but that the relationship is causal and consistent (Sadri \& Robertson, 1993).

A review of the IT literature suggests that the constructs identified by Bandura $(1977,1986)$ exist in the reactions of IT end users, but the definitions and distinctions are not always clearly made. For example, Davis et al. (1989) defined perceived ease of use as "the degree to which the prospective user expects the target system to be free of effort" (p. 173). This definition is closely linked to the definition of self-efficacy presented above by Bandura (1982). In other examples, Gist et al. (1989) found that self-efficacy influenced an individual's decision to learn a computer language, while Hill et al. (1987) reported that self-efficacy influenced an individual's decision to use computers.

Outcome expectancies have been less well defined and labeled in the IT literature. For example, Hill et al. (1987) found that "outcome beliefs" influenced the individual's decision to learn a computer language. Roskies, Liker, and Roitman (1988) found that employees in a large corporation did not believe they were personally able to influence event outcomes during a technological transformation. Furthermore, Kanter (1985) suggested that employees who find themselves in a position similar to that described by Roskies et al. may actually define themselves as "losers," implying a drastic reduction in self-efficacy and outcome expectancy. In another study, Rafaeli and Sutton (1986) examined the outcome beliefs of clerical personnel using a new word processing system and reported negative expectations about how using word processors would affect future work-related outcomes.

Several researchers have attempted to address the development of computer self-efficacy and outcome expectancy scales with varying degrees of success (e.g., Hill et al., 1987; Meier, 1985; Meier \& Lambert, 1991). As noted, the research to date has dealt mainly with students in experimental situations or volitional IT use in single organizations (Davis et al., 1989; Meier \& Lambert, 1991). In organizational IT research, self-efficacy and outcome expectancy are rarely measured, and when they are measured the constructs have not been extensively examined for reliability and validity. The purpose of this research is to extend previous work by developing constructs of computer self-efficacy and outcome expectancy across different organizations in which IT use is nonvolitional.

\section{METHOD}

\section{Scale Items}

In order to ensure content validity of the scales to be developed, a literature review of similar scales was performed. The items used were adapted from the work of Meier $(1985,1988)$ and Henry and Stone (1993) and are a result of refinements made across numerous studies (e.g., Henry \& Stone, 1995b, 1995c). All the items made use of a 5 -point Likert-type scale ( 1 = strongly disagree, $2=$ disagree, $3=$ neutral, $4=$ agree, and $5=$ strongly agree). The development was done for an organizational setting. In fact, the focus of the de- velopment was for use across different types of IT as well as organizations. Our previous work suggests that outcome expectancy is bidimensional. That is, outcome expectancies tend to group according to work expectancies and personal expectancies. In order to develop the measures of computer self-efficacy, work outcome expectancy, and personal outcome expectancy, as well as to assess their psychometric properties, a series of questionnaire items was designed based on our previous work. The resulting questionnaire contained 9 demographic questions to collect information about the respondent and the respondent's firm. The questionnaire also included 23 items designed to measure computer self-efficacy, work-related outcome expectancy, and personal outcome expectancy.

\section{Sample}

The target population was business executives across a variety of functional business areas. This population was represented by a large, nationwide mailing list. From this mailing list, the potential recipients of the questionnaire were selected randomiy. A total of 2,000 names was selected from the mailing list to receive a questionnaire. Out of these 2,000 mailed questionnaires, 411 were returned in a usable fashion. This produced a $20.55 \%$ response rate. Given the relatively low response rate, the generalizability of the results of the study is a concern. Yet, this concern is linked primarily to the representativeness of the sample, which is discussed in greater detail in the Response Bias section.

In order to facilitate this research focus, respondents were classified on the basis of their self-reported volitional or nonvolitional computer use. The yes/no questionnaire item that respondents used to self-report their volitional or nonvolitional computer use was, "Are you required to use the computer system at work to get your job done?" A total of 105 respondents reporting volitional computer system use was eliminated, leaving a sample of 306 nonvolitional users.

\section{RESULTS}

In order to gain a clear view of the nonvolitional sample, the 306 respondents and their computer system use were profiled. All of the values representing the respondents' profile are displayed in Table 1.

\section{Measure Development}

A total of 23 items on the questionnaire were designed to measure the constructs of computer self-efficacy and the two outcome expectancies. Each item was theoretically expected to measure only one construct. Eleven items were designed to measure computer self-efficacy, 7 were designed to measure work-related outcome expectancy, and the remaining 5 questionnaire items were designed to measure personal outcome expectancy. The questionnaire responses to these items were examined to develop measures possessing satisfactory psychometric properties. This was accomplished by performing a series of confirmatory factor analyses to purify the measures (Rainer \& Harrison, 1993).

Each confirmatory factor analysis was performed using a structural equations approach. In each case, the questionnaire items were the indicants for their respective construct or latent variable. The indicants were affected by a disturbance term that was free to vary while its associated path to the indicant was set equal to 1 . The constructs of computer self-efficacy and the two outcome expectancies were exogenous to the model with variances set equal to 1 . 
Table 1

Respondent Profile

\begin{tabular}{|c|c|c|c|c|c|}
\hline \multicolumn{6}{|c|}{ Personal Demographics } \\
\hline Gender & $60 \%$ male & & $34 \%$ female & & $n=306$ \\
\hline Age & Average $=44$ years & $S D=10.53$ & Minimum $=21$ & Maximum $=74$ & $n=275$ \\
\hline $\begin{array}{l}\text { Years employed } \\
\text { in organization }\end{array}$ & Average $=11$ & $S D=8.17$ & Minimum $=1$ & Maximum $=42$ & $n=305$ \\
\hline $\begin{array}{l}\text { Level in } \\
\text { organization }\end{array}$ & $\begin{array}{c}\text { senior management } \\
54 \%\end{array}$ & $\begin{array}{l}\text { middle management } \\
\qquad 18 \%\end{array}$ & $\begin{array}{c}\text { operational management } \\
\qquad 15 \%\end{array}$ & $\begin{array}{l}\text { other } \\
13 \%\end{array}$ & $n=302$ \\
\hline \multicolumn{6}{|c|}{ Computer Use Demographics } \\
\hline $\begin{array}{l}\text { Number of times system } \\
\text { is used each day }\end{array}$ & $\begin{array}{l}16 \% \\
0-5\end{array}$ & $\begin{array}{c}19 \% \\
10-20\end{array}$ & $\begin{array}{c}10 \% \\
21-30\end{array}$ & $\begin{array}{c}33 \% \\
\text { More than } 30\end{array}$ & $n=304$ \\
\hline $\begin{array}{l}\text { Percentage of time spent using } \\
\text { computer system }\end{array}$ & Average $=46 \%$ & $S D=27.82$ & Minimum $=1 \%$ & Maximum $=99 \%$ & $n=304$ \\
\hline $\begin{array}{l}\text { Respondent's performance } \\
\text { using computer system }\end{array}$ & $3 \%$ poor rating & $17 \%$ neutral rating & $80 \%$ excellent rating & & $n=305$ \\
\hline
\end{tabular}

Additionally, these constructs were allowed to be pair-wise correlated. All the factor analyses were done using covariance analysis of linear structural equations (CALIS) in PC SAS Version 6.08 using maximum likelihood estimation.

The objective of performing these purifying factor analyses was to produce measures of the constructs with desirable psychometric properties. In order to purify these measures, the standardized path coefficient between each indicant and its measure (i.e., latent variable) was compared with the estimated variance of the disturbance term for the indicant. A measure's psychometric properties, as well as the fit between the implied model and the data, are generally improved when indicants with low standardized path coefficients and/or large estimated disturbance term variances are eliminated from the analysis. This comparison was based on dividing the standardized path coefficient by the estimated variance. The decision rule for the elimination of an indicant had two parts. First, all items with a ratio of standardized path coefficient to estimated variance of less than 1 were eliminated from the analysis. Second, these ratios for all items in a given construct's measure were examined as a group. Those items with ratios lower than the ratios of the other items in the measure by a value of 1 or more were dropped from the analysis.

Employing the decision rule, a total of four confirmatory factor analyses were performed to purify these three measures. All four factor analyses were done using the model and approach described earlier. The process of purification was stopped when no additional questionnaire items could be eliminated from the analysis. The fourth and final factor analysis contained 12 questionnaire items. Four items measured computer self-efficacy, another 5 measured work-related outcome expectancy, and the remaining 3 items measured personal outcome expectancy. The measures of these constructs and the 12 questionnaire items forming them are shown in Table 2.

\section{Response Bias}

The profile of the respondents shown in Table 1 indicates that a wide range of potential respondents is captured in the sample, which helps reduce the potential for response bias. In order to examine the possible presence of response bias, the respondents were partitioned as early and late respondents (Armstrong \& Overton, 1977). The early and late respondents were compared across their demographic variables for the presence of any differences indicating response bias. The early respondents were defined as the lower quartile ( 77 respondents) when ordered by return date. The late respondents were those in the upper quartile ( 76 respondents) when ordered by return date.

These two groups of respondents were compared across personal and computer usage demographics using onetailed $t$ tests. For all of these tests, no meaningful differences were found between early and late respondents. These demographics and the corresponding values for the $t$ tests were as follows: gender $[t(151)=1.49, p=.14]$, age $[t(136)=-0.21, p=.83]$, years employed in the organization $[t(151)=0.67, p=.51]$, the respondent's level in the organization $[t(148)=0.78, p=.43]$, the number of times each day the respondent uses the computer system $[t(150)=$ $-0.18, p=.86]$, the percentage of time spent using the computer system $[t(149)=0.27, p=.78]$, and the respondents' evaluation of their performance using the computer system $[t(142)=-1.00, p=.32]$.

In order to further examine the possible presence of response bias, the scales measuring computer self-efficacy, personal outcome expectancy, and work-related expectancy were compared across these early and late respondents using $t$ tests. The measures were formed by summing the responses to each questionnaire. None of the tests indicated meaningful differences using a .05 significance level and a two-tailed test. These $t$ values were computer self-efficacy $[t(124)=-2.21, p=.06]$, personal outcome expectancy $[t(138)=-1.78, p=.16]$, and work-related outcome expectancy $[t(146)=-1.37, p=.34]$. However, if a less stringent significance level is used (e.g., .10), computer self-efficacy scores differed across early and late respondents, with early respondents displaying lower computer self-efficacy. Because the differences are not significant when the more typical significance level of .05 is 
Table 2

Measures, Questionnaire Items, Factor Loading, Reliabilities, and Average Percentage of Shared Variance

\begin{tabular}{|c|c|c|c|}
\hline Questionnaire Items & $\begin{array}{c}\text { Factor } \\
\text { Loading }\end{array}$ & $\begin{array}{c}\text { Reliability } \\
\text { Coefficient }\end{array}$ & $\begin{array}{c}\text { Shared } \\
\text { Variance }\end{array}$ \\
\hline Computer self-efficacy & & .85 & $59 \%$ \\
\hline $\begin{array}{l}\text { 1. At work, I feel more competent with the computer system than most other people. } \\
\text { 2. I know enough about the computer system to get my job done. } \\
\text { 3. Compared to other people at work, I know a lot about the computer system. } \\
\text { 4. I use the computer system as much as possible. }\end{array}$ & $\begin{array}{l}.86 \\
.67 \\
.77 \\
.76\end{array}$ & & \\
\hline Work-related outcome expectancy & & .88 & $60 \%$ \\
\hline $\begin{array}{l}\text { 5. In general, the system makes it easier for me to perform my job. } \\
\text { 6. Knowing how to use the computer system leads to higher quality work. } \\
\text { 7. Working with the computer system results in my completing my work on time. } \\
\text { 8. I believe that I am more productive at work when using the computer system. } \\
\text { 9. The computer system is useful for me in obtaining my goals at work. }\end{array}$ & $\begin{array}{l}.80 \\
.80 \\
.70 \\
.85 \\
.71\end{array}$ & & \\
\hline Personal outcome expectancy & & .89 & $73 \%$ \\
\hline $\begin{array}{l}\text { 10. Knowing how to use the computer system will help advance my career. } \\
\text { 11. Knowing how to use the computer system will increase the types of jobs for which I am qualified. } \\
\text { 12. Knowing how to use the computer system will make me more attractive for other firms to hire. }\end{array}$ & $\begin{array}{l}.81 \\
.91 \\
.84\end{array}$ & & \\
\hline
\end{tabular}

employed, we concluded that response bias did not appear to be a serious problem.

Moreover, given the research focus, the 105 volitional users were examined in some detail. The scales of computer self-efficacy, work-related, and personal outcome expectancy were summated for the appropriate questionnaire items for both volitional and nonvolitional users. These summated scales were then compared across volitional and nonvolitional users using $t$ tests. All tests indicated that there were meaningful differences between volitional and nonvolitional computer users. In all cases, volitional users had lower mean scores on these constructs than did nonvolitional users. For computer self-efficacy, the nonvolitional users had a summated score mean of 16.56 , whereas the volitional users' mean was $14.59[t(132)=$ $4.80, p<.01]$. The means across these groups for workrelated outcome expectancy were 21.93 and 20.08 for nonvolitional and volitional users, respectively $[t(132)=$ $4.50, p<.01]$. For personal outcome expectancy, the mean values for the scales were 11.83 for nonvolitional users and 10.38 for volitional users $[t(140)=4.11, p<.01]$.

A possible explanation for these meaningful differences comes from fundamental differences in the characteristics of volitional and nonvolitional users. The volitional users, on average, have less computer experience, have worked in the organization longer, and use the system less frequently in terms of number of times per day and percentage of time than nonvolitional users. This profile appears to show volitional users as less experienced with computers than nonvolitional users and as using IT less frequently.

\section{Psychometric Properties}

The psychometric properties examined for the measures were reliability (i.e, item and composite), average percentage of shared variance, and discriminant validity. All make use of the results from the final confirmatory factor analysis. In addition, on the basis of these results, conclusions were reached regarding the measures' convergent and construct validity. From the final confirmatory factor analysis, all the factor loadings or standardized path coefficients were computed. These factor loadings ranged from .67 to .91 . The reliability coefficients for these three measures were also computed from this confirmatory factor analysis. The reliability coefficient for computer self-efficacy was .85 ; this value was .88 and .89 for the work-related and personal outcome expectancy measures, respectively. In addition, the average percentage of shared variance was computed for each measure. For computer self-efficacy, the shared variance was $59 \%$, whereas for work-related outcome expectancy, the shared variance was $60 \%$. The shared variance for personal outcome expectancy was $73 \%$. These questionnaire items, factor loadings, reliabilities, and average percentage of shared variances are also shown in Table 2 .

Discriminant validity was also examined. Measures of two constructs demonstrate discriminant validity if the squared correlation between them is less than the average percentage of shared variance for both measures. For the three measures examined, the squared correlations were .48 for computer self-efficacy and work-related outcome expectancy, .18 for computer self-efficacy and personal outcome expectancy, and .26 for work-related outcome expectancy and personal outcome expectancy. Comparing these squared correlations with the average percentage of shared variance of each measure shown in Table 2 indicates that all the measures satisfy discriminant validity (Fornell \& Larcker, 1981).

To examine discriminant validity further, the questionnaire items were summed to form measures of each construct. One questionnaire item was then selected and removed from its summated score and correlated with all the summated scales. This process was repeated for each questionnaire item. An item demonstrates discriminant validity if it correlates more highly with its scale with itself removed than with all other summated scores. All the 
Table 3 Correlations Among Questionnaire Items

\begin{tabular}{rrrrrr}
\hline & 1 & 2 & 3 & 4 & \\
\cline { 1 - 3 } 1 & 1.00 & & & & \\
2 & .56 & 1.00 & & & \\
3 & .76 & .43 & 1.00 & & \\
4 & .64 & .53 & .58 & 1.00 & \\
5 & .47 & .56 & .38 & .60 & \\
6 & .43 & .52 & .35 & .58 & \\
7 & .34 & .41 & .28 & .48 & \\
8 & .44 & .49 & .37 & .60 & \\
9 & .42 & .49 & .30 & .53 & \\
10 & .34 & .29 & .30 & .34 & \\
11 & .32 & .32 & .29 & .31 & \\
12 & .35 & .37 & .30 & .36 & \\
& 5 & 6 & 7 & 8 & 9 \\
\hline 5 & 1.00 & & & & \\
6 & .71 & & 1.00 & & \\
7 & .62 & & .61 & 1.00 & \\
8 & .70 & & .66 & .68 & 1.00 \\
9 & .62 & & .58 & .60 & .66 \\
10 & .36 & .39 & .38 & .44 & .38 \\
11 & .35 & .39 & .41 & .40 & .36 \\
12 & .35 & .40 & .39 & .43 & .38 \\
& 10 & 11 & 12 & & \\
\hline 10 & 1.00 & & & & \\
11 & .75 & 1.00 & .00 & & \\
12 & .66 & .78 & 1.00 & & \\
\hline
\end{tabular}

Note-The numbers correspond to the numbered questionnaire items in Table 2.

computed correlations showed that the questionnaire items correlated more highly with their own scales without the item than with any other summated score. Thus, these results provide evidence of satisfactory discriminant validity. It was also the case that the intercorrelations among all the questionnaire items were computed. These correlations are reported in Table 3.

To investigate the validity of these scales further, an external variable was developed and correlated with computer self-efficacy and the two outcome expectancies. The external variable was behavioral intention to use computers. The specific items in the scale were: "I intend to spend more time at work using the computer system," "I intend to learn how to use the computer system more fully in my job," and "I intend to integrate the computer system into my work more." Logically, behavioral intentions to use the computer system should be related in a meaningful fashion to computer self-efficacy, work-related outcome expectancy, and personal outcome expectancy. Individuals reporting high scores on computer self-efficacy should be willing to expand the use of the computer system at work. Similarly, if individuals have high scores on work-related and personal outcome expectancy, they would be likely to perceive positive and meaningful results from using the computer system at work. Thus, behavioral intentions would be positively correlated with computer self-efficacy, workrelated outcome expectancy, and personal outcome expectancy. If these correlations are positive, meaningfully large, and statistically significant, they would show that the scales in question are related to an external construct (i.e., behavioral intentions).

The estimation of these correlations was done using confirmatory factor analysis and a structural equations approach with maximum likelihood estimation. The measures of the constructs were allowed to pair-wise correlate and each had a standard deviation set equal to 1 . Each questionnaire item was used as an indicant for only one construct. No disturbance terms were allowed to correlate. The resulting estimation had a goodness-of-fit index (GFI) of .87 and an adjusted GFI of .83 . Bentler and Bonett's (1980) nonnormed and normed fit indexes were .91 and .89. Bollen's normed and nonnormed indexes were .87 and .92. The correlations among these constructs were .62 between behavioral intentions and computer self-efficacy, .63 between behavioral intentions and work-related outcome expectancy, and .61 for behavioral intentions and personal outcome expectancy. All these correlations were statistically significant at the .01 level.

The meaningful, significant, and positive correlations between these scales and behavioral intentions to use the IT at work lend support to the conclusion that the scales in question possess validity. Additionally, computer selfefficacy and outcome expectancies have been shown to relate in a meaningful fashion with a variety of other constructs in theoretically sound frameworks. These constructs, measured using similar scales, include job performance, computer system satisfaction, and job satisfaction (Henry $\&$ Stone, 1994, 1995a, 1995c). These results and those from previous studies across a variety of settings lend additional evidence supporting the construct validity of the self-efficacy scale and both outcome expectancies scales.

In summary, the psychometric properties of these measures were satisfactory. This statement is based on the following observations from the confirmatory factor analysis results. First, item reliability was satisfied since all the factor loadings (i.e., standardized path coefficients) were larger than .65 . Second, since all the reliability coefficients were .85 or higher, composite reliability was satisfied (Nunnally, 1978). Third, since the average percentage of shared variance for each measure was larger than $50 \%$, these measures display satisfactory values of shared variance (Igbaria \& Greenhaus, 1992). From these results, it can be concluded that the measures display satisfactory convergent validity (Rainer \& Harrison, 1993). The demonstration of convergent and discriminant validity suggests that the measures possess construct validity (Rainer $\&$ Harrison, 1993). These results are based on commonly used procedures to evaluate the validity of such scales. Other authors have proposed multitrait-multimethod techniques, often viewed as more rigorous than those used in this study (Meier, 1994). The evaluation of these constructs using these methods warrants future research.

Given the desirable psychometric properties of these measures, the empirical results of interest are the fit of the confirmatory factor analysis to the data. Several statistics summarize this fit and are presented in Table 4. The GFI was .91, while this same index adjusted for the $d f$ in the 
Table 4

Summary Statistics for Fit of Confirmatory Factor Analysis to Data

\begin{tabular}{lc}
\hline Goodness-of-fit index & .91 \\
Adjusted goodness-of-fit index & .86 \\
Root mean square residual & .06 \\
Chi-square statistic $(d f=51)$ & $162.00^{*}$ \\
Bentler's comparative fit index & .94 \\
Bentler \& Bonett's nonnormed index & .93 \\
Bentler \& Bonett's normed index & .92 \\
Bollen's nonnormed index & .94 \\
Bollen's normed index & .90 \\
\hline
\end{tabular}

${ }^{*} p<.01$.

model was .86 . The root mean square residual was .06 , and the chi-square statistic was 162.00 . The chi-square statistic had $51 d f$ and was significant at the .01 level. In addition, Bentler's (1980) comparative fit index had a value of .94. Four incremental fit indexes (i.e., Bentler \& Bonett's, 1980 nonnormed and normed indexes and Bollen's nonnormed and normed indexes) had computed values of $.93, .92, .94$, and .90 , respectively. On the basis of these statistics, it can be concluded that the fit of the confirmatory factor analysis to the data appears to be acceptable (Hair, Anderson, Tatham, \& Black, 1992).

The details from the estimation of the model are shown in Figure 1. All the standardized path coefficients between the measures and their indicants were significant at the .01 level. Further, the variances of these disturbance terms were statistically significant at the .01 level. Also shown in Figure 1 are the correlations between these measures, which were statistically significant at the .01 level.

\section{DISCUSSION}

The empirical analysis generated three conceptually meaningful constructs measuring computer self-efficacy, work-related expectancy, and personal outcome expectancy. Conceptually, such measures have been shown to operate as "cognitive mediators of action" (Bandura, 1986). As indicated by the self-efficacy items, expectations of needed skills and technical knowledge all indicate an individual's capability to perform computer-related tasks. Past research has shown that self-efficacy can influence motivation and behaviors in achievement-oriented contexts (Peterson \& Barrett, 1987; Peterson \& Seligman, 1984; Peterson \& Villanova, 1988; Seligman, 1990; Seligman \& Schulman, 1986). We have used earlier versions of these scales to model the effect of expectations and the antecedents of expectations on important criterion variables in information systems research (e.g., job performance, Henry \& Stone, 1993, 1995c; end-user satisfaction, Henry \& Stone, 1994; and job satisfaction, Henry \& Stone, 1995a).

However, most interesting in this study was the conceptualization of two distinct outcome expectancies. Bandura (1977) recognized the similarities of his self-efficacy theory to similar motivational models proposing that effort and performance are based on both intrinsic and extrinsic rewards (Porter \& Lawler, 1968; Weirsma, 1992). In fact, Bandura (1977) stated in his introduction of selfefficacy theory:

The preceding analysis of how perceived self-efficacy influences performance is not meant to imply that expectation is the sole determinant of behavior. Expectation alone will not produce desired performance if the component capabilities are lacking. Moreover, there are many things that people can do with certainty of success that they do not perform because they have no incentives to do so. Given appropriate skills and adequate incentives, however, efficacy expectations are a major determinant of people's choice of activities, how much effort they will expend, and of how long they will sustain effort dealing with stressful situations. (1977, p. 194)

However, some researchers have argued that task performance is not an appropriate variable for measuring intrinsic rewards because it may reflect both intrinsic and extrinsic rewards and, as a result, should be separated

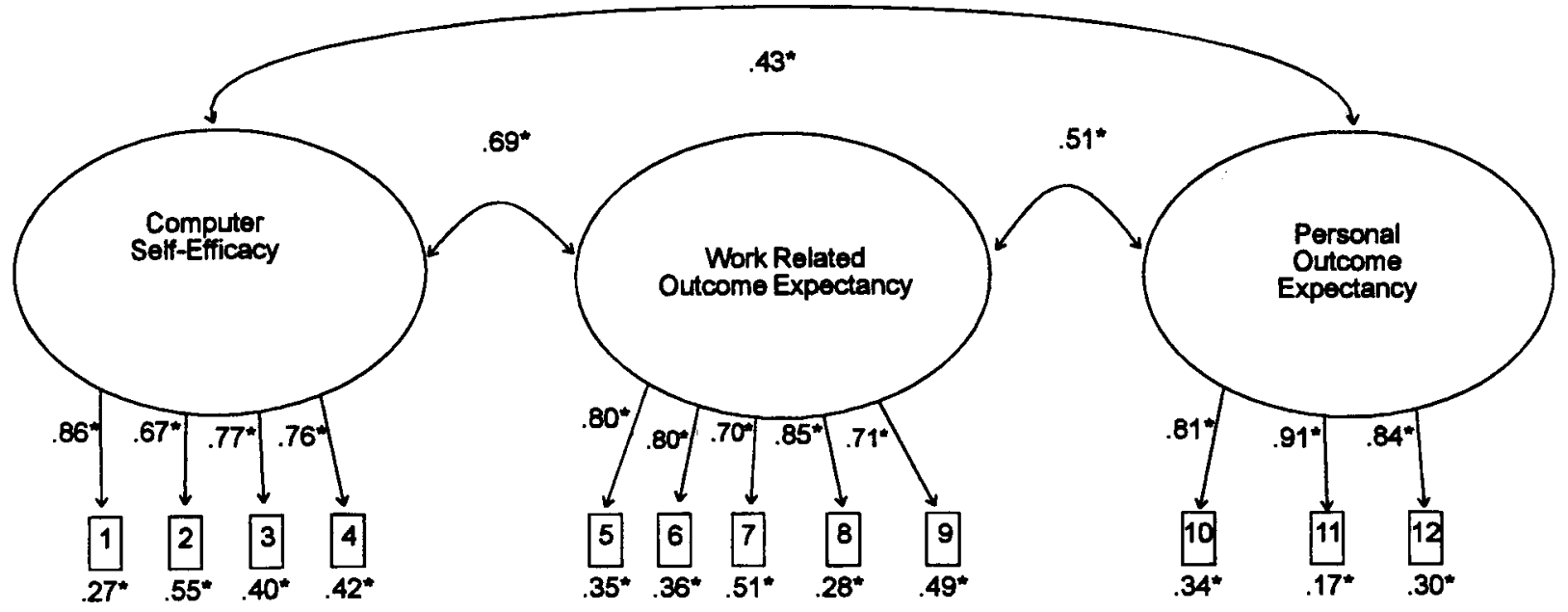

Figure 1. The relationship between the measures and indicants using standardized coefficients $(p<.01)$. 
(Wiersma, 1992). This study shows that the similar constructs of personal and work-related outcome expectancies can be separated successfully in organizational contexts. Thus, the notion of outcome expectancy appears to enhance the use of self-efficacy as an independent variable. For example, in three different studies, Henry and Stone $(1994,1995 \mathrm{a}, 1995 \mathrm{c})$ found that computer self-efficacy and outcome expectancy mediated the effects of previous experience, management support, IT ease of use on job performance, IT satisfaction, and end user perceptions of the quality of patient care in a hospital.

Moreover, according to Maddux et al. (1986), "the predictive usefulness of outcome expectancy depends largely on the degree to which it can be distinguished from selfefficacy expectancy" (p. 784). This study has shown outcome expectancy to be bidimensional and separate from self-efficacy. Similar measures used in past research have revealed an unacceptable overlap between self-efficacy and outcome expectancy, thus blurring the distinction between the measures (Eastman \& Marzillier, 1984). Additionally, self-efficacy and outcome expectancy have generally been shown in the past to be domain specific. However, Bandura (1982, 1986) and Marsh, Smith, Barnes, and Butler (1983) have shown that generalizations can be made across similar domains. This is another important contribution of the current research. It is expected that future refinement of these questionnaire items and constructs will enhance the measures' psychometric properties. Given the general scarcity of theoretical models to guide IT researchers, the development of computer self-efficacy and outcome expectancy and their future refinement are of importance and interest. Since many interesting theoretical models and explanations can be developed on the basis of self-efficacy and outcome expectancy, these measures and their future refinement should be explored in future research, especially as IT use becomes increasingly nonvolitional.

\section{CONCLUSION}

Future research based upon these results should take two directions. First, the measures of computer self-efficacy and outcome expectancy should be refined through additional measure development studies. Such studies would hopefully improve and verify the measures and psychometric properties identified here. Second, additional empirical research needs to be performed regarding the relationships between these measures and related variables such as job performance, job satisfaction, and IT satisfaction. It is these and similar relationships that are of interest in terms of positive end-user perceptions of nonvolitional IT systems.

\section{REFERENCES}

Armstrong, J. S., \& OVERTon, T. S. (1977). Estimating nonresponse bias in mail surveys. Journal of Marketing Research, 14, 396-402. BANDURA, A. (1977). Self-efficacy: Toward a unifying theory of behavioral change. Psychological Review, 84, 191-215.
Bandura, A. (1982). Self-efficacy mechanism in human agency. American Psychologist, 37, 122-147.

BANDURA, A. (1986). Social foundation of thought and action: $A$ social cognitive theory. Englewood Cliffs, NJ: Prentice-Hall.

Baronas, A. K., \& Louts, M. R. (1988). Restoring a sense of control during implementation: How user involvement leads to system acceptance. MIS Quarterly, 12, 111-126.

Bentler, P. M. (1980). Multivariate analysis with latent variables: Causal modeling. Annual Review of Psychology, 31, 419-456.

Bentler, P. M., \& Bonett, D. G. (1980). Significance tests and goodness-of-fit in the analysis of covariance structures. Psychological Bulletin, 88, 588-600.

COOPER, C. L., \& ZMUD, R. W. (1990). Information technology implementation research: A technological diffusion approach. Management Science, 36, 123-139.

DAVIS, F. D. (1986). A technology acceptance model for empirically testing new end-user information systems: Theory and results. Unpublished doctoral dissertation, MIT.

Davis, F. D., Bagozzi, R. P., \& Warshaw, P. R. (1989). User acceptance of computer technology: A comparison of two theoretical models. Management Science, 35, 982-1003.

Doll, W. J., \& ToRKZADEH, G. (1996). Measuring how information technology is used in an organizational context. Unpublished manuscript.

Eastman, C., \& MARzILLIER, J. (1984). Theoretical and methodological difficulties in Bandura's self-efficacy theory. Cognitive Therapy \& Research, 8, 213-229.

FISHBEIN, M., \& AJZEN, I. (1975). Belief, attitude, intention and behavior: An introduction to theory and research. Reading, MA: Addison-Wesley.

ForNell, C., \& LARCKER, D. F. (1981, February). Evaluating structural equation models with unobservable variables and measurement error. Journal of Marketing Research, 18, 39-50.

GatTiKer, U. E., \& HlavkA, A. (1992). Computer attitudes and learning performance: Issues for management education and training. Journal of Organizational Behavior, 13, 89-101.

GisT, M. E., \& Mitchell, T. R. (1992). Self-efficacy: A theoretical analysis of its determinants and malleability. Academy of Management Review, 17, 183-210.

Gist, M. E., Schwoerer, C., \& Rosen, B. (1989). Effects of alternative training methods on self-efficacy and performance in computer software training. Journal of Applied Psychology, 74, 884-891.

Gutek, B. A., Winter, S. J., \& Chudoba, K. M. (1992, August). Attitudes toward computers: When do they predict computer use? Paper presented at the annual meeting of the Academy of Management, Las Vegas.

HACKETT, G., \& BetZ, N. E. (1989). An exploration of the mathematics self-efficacy/mathematics performance correspondence. Journal for Research in Mathematics Education, 20, 261-273.

Hair, J. F., JR., Anderson, R. E., TATHAM, R. L., \& BlaCk, W. C. (1992). Multivariate data analysis with readings (3rd ed.). New York: Macmillan.

HENRY, J. W. (1989). Learned helplessness: A factor moderating the impact of technology in the workplace. Unpublished manuscript.

HENRY, J. W., \& MARTINKO, M. J. (1997). An attributional analysis of the rejection of information technology. Journal of End User Computing, 9(4), 3-17.

HenRY, J. W., \& Stone, R. W. (1993, October). The development and validation of computer self-efficacy and outcome expectancy scales. Paper presented at the annual meeting of the Institute of Management Sciences Southeastern Chapter, Myrtle Beach, SC.

HENRY, J. W., \& STONE, R. W. (1994). A structural equation model of end-user satisfaction with a computer-based medical information system. Information Resources Management Journal, 7, 21-33.

HENRY, J. W., \& STONE, R. W. (1995a). Computer self-efficacy and outcome expectancy: The effects on the end-user's job satisfaction. Computer Personnel, 16, 15-37.

HENRY, J. W., \& Stone, R. W. (1995b). Expert systems in the marketing organization. Journal of Health Information Management Research, 3, 1-16.

HENRY, J. W., \& STONE, R. W. (1995c). A structural equation model of job performance using a computer-based order entry system. Behaviour \& Information Technology, 14, 163-173. 
Henry, J. W., Stone, R. W., \& Pierce, M. A. (1995, December). Determinants of student performance in the introductory computer programming course in the college of business. Paper presented at the annual meeting of the International Academy of Information Management, New Orleans.

Hill, T., Smith, N. D., \& ManN, M. F. (1987). Role of efficacy expectations in predicting the decision to use advance technologies: The case of computers. Journal of Applied Psychology, 72, 307-313.

IgBaria, M., \& ChakrabarTI, A. (1990). Computer anxiety and attitudes toward microcomputer use. Behaviour \& Information Technology, 9, 229-241.

IgBaria, M., \& Greenhaus, J. H. (1992). Determinants of MIS employee's turnover intentions: A structural equation model. Communications of the ACM, 35, 35-49.

Igbaria, M., \& Parasuraman, S. (1989). A path analytic study of individual characteristics, computer anxiety and attitudes toward microcomputers. Journal of Management, 15, 373-388.

JaCobson, S. F., Holder, M. E., \& Dearner, J. F. (1989). Computer anxiety among nursing students, educators, staff, and administrators. Computers in Nursing, 7, 266-272.

JAY, T. (1981). Computerphobia: What to do about it. Educational Technology, 21, 47-48.

KANTER, R. M. (1985). Managing the human side of change. Management Review, 74, 52-59.

KwoN, T. H., \& ZMUD, R. W. (1987). Unifying the fragmented models of information systems implementation. In R. J. Boland, Jr., \& R. A. Hirscheim (Eds.), Critical issues in information systems research (pp. 227-251). New York: Wiley.

LaLomia, J. J., \& SidowSKI, J. B. (1991). Measurements of computer attitudes: A review. International Journal of Human-Computer Interaction, 3, 171-197.

Maddux, J. E., Norton, L. W., \& Stoltenberg, C. D. (1986). Selfefficacy expectancy, outcome expectancy, and outcome value: Relative effects on behavioral intentions. Journal of Personality \& Social Psychology, 51, 783-789.

Marsh, H. W., Smith, I. D., Barnes, J., \& Butler, S. (1983). Selfefficacy concept: Reliability, stability, dimensionality, validity, and the measurement of change. Journal of Educational Psychology, 75, 772790.

Martinko, M. J., Henry, J. W., \& ZMUd, R. W. (1996). Learned helplessness: $A$ theoretical explication of reactions to information technologies in the workplace. Unpublished manuscript.

MeIER, S. T. (1985). Computer aversion. Computers in Human Behavior, 1, 171-179.

MeIER, S. T. (1988). Predicting individual differences on computerbased tests and tasks: Development of the computer aversion scale. Computers in Human Behavior, 4, 175-187.

MEIER, S. T. (1994). The chronic crisis in psychological measurement and assessment. New York: Academic Press.

Meier, S. T., \& Lambert, M. E. (1991). Psychometric properties and correlates of three computer aversion scales. Behavior Research Methods, Instruments, \& Computers, 23, 9-15.
NeLSON, D. L. (1990). Individual adjustment to information-driven technologies: A critical review. MIS Quarterly, 14, 79-98.

Nelson, D. L., \& White, M. A. (1990). Management of technological innovation: Individual attitudes, stress, and work group attributes. Journal of High Technology Management Research, 1, 138-148.

Nunnally, J. (1978). Psychometric methods (2nd ed.). New York: McGraw-Hill.

OSKAMP, S. (1977). Attitudes and opinions. Englewood Cliffs, NJ: Prentice-Hall.

Pancer, S. M., George, M., \& Gebotys, R. J. (1992). Understanding and predicting attitudes towards computers. Computers in Human Behavior, 8, 211-222.

Peterson, C., \& Barrett, L. C. (1987). Explanatory style and academic performance among university freshmen. Journal of Personality \& Social Psychology, 53, 603-607.

Peterson, C., \& Seligman, M. E. P. (1984). Causal explanations as a risk factor for depression: Theory and evidence. Psychological Review, 91, 347-374.

Peterson, C., \& Villanova, P. (1988). An expanded attributional style questionnaire. Journal of Abnormal Psychology, 97, 87-89.

PoPE-DAVIS, D. B., \& TWING, J. S. (1991). The effects of age, gender, and experience on measures of attitude regarding computers. Computers in Human Behavior, 7, 333-339.

PORTER, L. W., \& LAWLER, E. E. (1968). Managerial attitudes and performance. Homewood, IL: Irwin Dorsey.

RAFAELI, A., \& SUTTON, R. I. (1986). Word processing technology and perceptions of control among clerical workers. Behaviour \& Information Technology, 5, 31-37.

RaINER, R. K., \& Harrison, A. W. (1993). Toward development of the end user construct in a university setting. Decision Sciences Journal, 24, 1187-1202.

Roskies, E., Liker, J. K., \& RoITMAN, D. B. (1988). Winners and losers: Employee perceptions of their company's technological transformation. Journal of Organizational Behavior, 9, 123-137.

SADRI, G., \& RoBERTSON, I. T. (1993). Self-efficacy and work-related behaviour: A review and meta-analysis. Applied Psychology: An International Review, 42, 139-152.

Seligman, M. E. P. (1990). Learned optimism. New York: Alfred A. Knopf.

Seligman, M. E. P., \& Schulman, P. (1986). Explanatory style as a predictor of productivity and quitting among life insurance sales agents. Journal of Personality \& Social Psychology, 50, 832-838.

WIERSMA, U. J. (1992). The effects of extrinsic rewards in intrinsic motivation: A meta-analysis. Journal of Occupational \& Organizational Psychology, 65, 101-114.

ZMUD, R. W. (1979). Individual differences and MIS success: A review of the empirical literature. Management Science, 25, 966-979.

(Manuscript received October 31, 1995; revision accepted for publication October 10, 1996.) 